\title{
DIAGNÓSTICO DEL SISTEMA DE PARTIDOS EN REPÚBLICA DOMINICANA: PADECIMIENTOS -RECIENTES Y AÑEJOS-, SÍNTOMAS DE MEJORÍA Y ALGUNAS RECETAS PARA SU MODERNIZACIÓN
}

Diagnosis of the Party System in Dominican Republic: Suffering-Recent-Vintage, Symptoms Improvement and Some Recipes for Modernization

\section{Rafael Toribio Ana Belén Benito Sánchez}

Resumen: A punto de cumplirse una década desde la desaparición de los tres caudillos que dominaron la política dominicana por más de treinta años, resulta oportuno preguntarse cuáles han sido las rupturas y cuáles las inercias en el sistema de partidos de la República Dominicana. Con este propósito, se elaboró un diagnóstico que evaluara el nivel de institucionalización, democracia interna y transparencia de los partidos políticos en los últimos cinco años y cuyos avances se presentan en este trabajo. Escenarios en apariencia contradictorios de debilidad institucional y de fuerza electoral, parecen ser los rasgos distintivos que caracterizan al sistema en la actual etapa de la consolidación democrática.

Palabras claves: República Dominicana, sistema de partidos, institucionalización, transparencia, democracia interna. 
Abstract: After ten years since the disappearance of the three leaders who dominated the Dominican politics for more than thirty years, It must be asked which have been the breaks and which the inertia in the Dominican Party System. Those are the objectives of the Diagnostic, which evaluated the level of institutionalization, internal democracy and transparency of the political parties in the last five years. Institutional weakness and electoral force are the distinctive features of the current phase of the democratic consolidation in the country.

Keywords: Dominican Republic, party system, institutionalization, transparency, internal democracy.

\section{El diagnóstico}

En los últimos años, la crisis de los partidos políticos en América Latina ha ocupado un lugar destacado en la literatura especializada y en los medios de comunicación. Sociólogos, politólogos y analistas políticos han señalado la crisis de legitimidad, credibilidad y de liderazgo, como principales raíces de la escasa confianza de los ciudadanos en sus políticos y del mayor protagonismo de la sociedad civil en la escena pública. Esta crisis afecta de manera directa la calidad de la democracia en la región, ya que los partidos políticos son instituciones claves de la representación, encargados de canalizar el interés público y generar aspiraciones colectivas. En este escenario, se hacía necesario conocer cuál era el estado de la cuestión en República Dominicana para trazar los retos y delinear las oportunidades de renovación de sus partidos, contribuyendo así a la mejora de la calidad de la democracia en la actual etapa de la consolidación democrática en que vive el país. 
¿Cuál es el estado de salud democrática de los partidos políticos dominicanos? ¿Qué factores de riesgo amenazan el juego de la competencia? ¿Serán el personalismo y la desideologización enfermedades crónicas? Estas preguntas guían el Diagnóstico sobre la situación del sistema de partidos en República Dominicana 2005-2010 elaborado por el Programa de Formación y Gerencia Política (PFGP) ${ }^{1}$, en colaboración y auspicio con el Instituto Interamericano de Derechos Humanos y el Centro de Asistencia y Promoción Electoral (IIDH/CAPEL). El objetivo ha sido obtener una radiografía fidedigna del panorama partidario en el país a través no solo del análisis del marco normativo supranacional e interno de los partidos, sino del contexto alternativo de reglas informales que rigen la vida partidaria dominicana. La rutina y la vorágine electoral han entretejido un complejo escenario de procedimientos informales que los actores políticos conocen y dominan, es por ello que se hizo necesario consultar a sus protagonistas para que dibujaran ese otro "manual de instrucciones" que acompaña al marco formal que describen las normas.

Se tomaron tres radiografías del sistema de partidos dominicanos bajo el lente de la Institucionalización, el de la Democracia Interna y el de la Transparencia y el diagnóstico fue un panorama de fragilidad institucional cuya máxima expresión es el incumplimiento de los estatutos y la ausencia de sanciones. En este escenario, priman los arreglos informales para solventar las controversias de la vida de los partidos dominicanos. Viejas prácticas como el caudillismo, la personificación de la política y el clientelismo, siguen dominando la relación entre políticos y electores en República Dominicana, ahora utilizadas con destreza por los nuevos actores. La ausencia de proyecto colectivo y la desideologización son suplidas con la promesa individual y el intercambio de prebendas, convirtiendo al partido en mera maquinaria electoral al servicio del candidato. Este diagnóstico constata

1 PFGP (2011). Diagnóstico sobre la situación del sistema de partidos en la República Dominicana 2005-2010: análisis del marco normativo y visión de los actores. Santo Domingo: USAID, CAPEL, PFGP. 
que el voto preferencial ha exacerbado las luchas internas, y que las elecciones primarias y la renovación de autoridades partidarias engendran batallas que debilitan al partido. El relevo generacional y la participación de la mujer en condiciones de equidad, encuentran la resistencia de las viejas figuras y de los propios compañeros de partido.

No obstante, se trata de una radiografía que muestra paisajes esperanzadores, destacando por novedosa la regulación constitucional de las funciones de los partidos políticos, en un ejercicio que supera la concepción puramente electoralista de la legislación anterior. Por primera vez se establecen como funciones esenciales de los partidos políticos la satisfacción del bienestar colectivo y el interés general. Estas previsiones exigen una adaptación del modo de concebir el ejercicio de la política y la función pública en el país, y ameritan un cambio en la legislación actual. Sin embargo, la resistencia de los protagonistas se hace evidente en las dilaciones interesadas en la aprobación del Anteproyecto de Ley de Partidos Políticos, que desde más de una década se intenta su aprobación en el Congreso. Las voces de los jóvenes políticos y las mujeres emergen con fuerza en este diagnóstico: resistiéndose a ser meros "llena guaguas", reclamando acceso a los recursos para poder competir en igualdad de condiciones, y denunciando los vicios que acechan al quehacer político diario: alianzas que prorratean puestos e instituciones, liderazgos que se construyen en base a proyectos personales sin visión de país, y débil fiscalización de fondos, donantes y favores prometidos que hay que devolver.

\section{Padecimientos}

En la elaboración de esta radiografía sobre el sistema de partidos, se siguió el protocolo metodológico utilizado en el anterior diagnóstico Democratización de los partidos políticos en Bolivia, Chile y República Dominicana (Rosales y Valverde, 2006) y que comprende 13 indicadores de existencia normativa correspondientes a las tres dimensiones analizadas: 
institucionalización, democracia interna y transparencia. Además se realizaron una serie de grupos focales con actores clave del sistema de partidos para poder mostrar la constante dicotomía entre lo formal y lo informal que caracteriza el quehacer partidario en el país.

\section{LAS REGLAS DEL JUEGO INTERPARTIDARIO A NIVEL NACIONAL}

Los partidos políticos, relegados en la Constitución de 1994 al Título XII, dedicado a las "Disposiciones Generales" (artículo N. ${ }^{\circ} 104$ ), pasan ahora en la nueva Constitución de 2010 al Capítulo III del Título X dedicado al "Sistema Electoral". Este reconocimiento diferenciado viene acompañado de una descripción de funciones ausente en la Constitución anterior y tan importantes como: canalizar la participación ciudadana, garantizar el pluralismo en la elección de cargos públicos, servir al interés nacional y al bienestar colectivo (artículo N. ${ }^{\circ}$ 216). La enumeración de estas funciones de marcado carácter inclusivo y general, es especialmente significativa ya que, el personalismo y la ausencia de proyecto colectivo caracterizan la relación entre ciudadanos y políticos en la República Dominicana. Además supone un avance con respecto a la conceptualización meramente electoralista de la Ley $\mathrm{N}^{\circ} 275$ de 1997, que atribuye a los partidos políticos el fin primordial de ser el vehículo que permite la elección de cargos públicos (artículo N. ${ }^{\circ} 41$ ), sin referencia alguna al contenido sustantivo. Ninguno de los textos acoge formalmente una definición de partido político, salvo la enumeración de los requisitos para su válida conformación. No obstante, es revelador que la Ley Electoral de 1997 exija para su reconocimiento respetar la Constitución y las leyes, mientras que la nueva Carta Magna añade la necesidad de que tanto su conformación como su funcionamiento se sustenten en el respeto de la democracia interna y la transparencia.

La valoración del eje Institucionalización es por tanto positiva con respecto al diagnóstico del período anterior, por la importancia del reconocimiento constitucional de los partidos políticos y la descripción de funciones esenciales de carácter colectivo/inclusivo, frente al intercambio particularizado y personal del clientelismo dominante 
(Benito y Rosales, 2011: 13). En este sentido es ilustrativa la opinión que expresaba uno de los entrevistados:

Los partidos politicos hemos influido en que los dominicanos no podamos trascender el inmediatismo, trascender de lo personal a lo colectivo (...) Si escuchas a cualquier compañero te das cuenta de que él tiene una serie de proyectos y propuestas que tienen que ver con la gente de su pueblo para que lo apoye, pero no necesariamente con el bienestar colectivo de la sociedad dominicana.

Con respecto a la dimensión Democratización, la Constitución de 2010 no ha supuesto cambios fundamentales más allá de la mera exigencia de democracia interna que debe regir el funcionamiento de los partidos políticos. Al igual que la Constitución de 1994, no contempla la presencia de órganos tipo "tribunal interno", un número mínimo de militantes ni de organización en las provincias, ni cuotas afirmativas en sus órganos de dirección (mujeres, jóvenes, discapacitados, grupos étnicos). Sin embargo, con respecto a las mujeres, la actual Constitución en su artículo N. ${ }^{\circ} 39$ consagra el deber del Estado de promover y garantizar la participación equilibrada de mujeres y hombres en las candidaturas a los cargos de elección popular en el ámbito público, en la administración de justicia y en los órganos de control del Estado, por lo que esta previsión de carácter general a nivel constitucional ha tenido desarrollo legislativo. Tal es el caso de la cuota del $33 \%$ que establece la Ley Electoral en su artículo N. ${ }^{\circ} 68$ y el $50 \%$ para el caso de las sindicaturas y vicesindicaturas de la Resolución 4/2010. A pesar de estas previsiones, en las elecciones legislativas y municipales de mayo de 2010, la Junta Central Electoral (JCE) obligó a los partidos mayoritarios a corregir las irregularidades detectadas en las listas al no cumplir con la cuota femenina. Esta medida de discriminación positiva, encuentra las dificultades de la resistencia de los propios compañeros de partido; las barreras de una cultura política machista que reserva el espacio público a los hombres y en el que las mujeres son meros agentes de movilización; y principalmente, el acceso al financiamiento de la mujer política. A pesar de que la Ley Electoral de 1997 exige cierta organización provisional 
en cada municipio, no existe el deber de garantizar posteriormente la permanencia organizativa del partido, por lo que hay que concluir que esta provisionalidad resiente la institucionalización, ya que la estructura partidaria pasa a ser mera máquina electoral al servicio del candidato que desaparece tras las elecciones (Benito y Rosales, 2011: 14).

Con respecto a la Transparencia, salvo la mención del artículo N. ${ }^{\circ} 216$ de la actual Constitución, no hay cambios significativos en los cinco indicadores de esta dimensión. El financiamiento y la publicidad de las cuentas del partido no es un mandato constitucional sino legislativo, siendo la Ley Electoral de 1997 la que regula estos importantes aspectos. En ella se estableció la aportación pública regular a los partidos, que hasta entonces dependían únicamente de las donaciones privadas. A pesar de que los partidos políticos han de presentar informes de sus estados financieros, a un mes de las pasadas elecciones de 2010 no todos los partidos habían cumplido con esta obligación.

\section{LAS REGLAS DEL JUEGO INTERNO}

\section{A) Institucionalización}

\section{Eje 1 - Estatutos, principios y reglas formales de organización}

Los partidos cuentan con Estatutos y detallan cuál es el órgano encargado de su promulgación pero sin especificar el procedimiento de promulgación. La misma ambigüedad se refleja a la hora de especificar el procedimiento de reforma. En estos cinco años que comprende el estudio, la mayoría de los partidos han reformado sus estatutos. En ocasiones, y producto de la ambigüedad normativa, estas reformas estatutarias han tenido como objetivo legitimar actuaciones que no se ajustaban a lo establecido en la normativa básica, en una suerte de formalización de los arreglos informales que imperan en la vida del partido. $\mathrm{Y}$ es que, como atestiguan los actores entrevistados, el incumplimiento de los estatutos es una de las constantes e indicador de debilidad institucional: 
Es necesario participar en los procesos entendiendo a las reglas no escritas.

La debilidad ideológica/programática de los partidos dominicanos se ha acentuado tras la desaparición de los caudillos históricos que proporcionaban sustento ideológico a los mismos. En este escenario, el clientelismo y el particularismo son las armas de movilización del electorado dominicano (Benito y Rosales, 2011: 17). Así lo constatan los protagonistas de la escena política entrevistados:

Una de las grandes debilidades de los partidos politicos en la República Dominicana es su pérdida de identidad (...), los liderazgos no se desarrollan en base a proyectos de país, sino a proyectos personales (...) las aspiraciones colectivas fueron desplazadas por las individuales (...) La gente entiende que tú eres un buen líder en la medida en que resuelves sus problemas personales, no los problemas colectivos.

La debilidad ideológica se manifiesta también en el juego de alianzas que caracteriza la interacción partidista de los últimos años en el país. Lejos de consensuar agendas programáticas con partido ideológicamente afines, los compañeros de pacto se eligen en función de los puestos a repartir:

La politica en la República Dominicana se ha convertido en alianzas para poder ocupar espacios (...) No discutimos alianzas en procesos de negociación con una plataforma ideológica para que el país avance. Las negociaciones se bacen en base a cuotas de poder de los candidatos y expresan la propuesta individual del candidato.

\section{Eje 2 - Membresía, militancia}

Los partidos contemplan en su normativa estatutaria y reglamentaria un apartado dedicado a miembros y militantes, catálogo de derechos y deberes, procedimiento para la adquisición de tal condición, así como el órgano encargado de llevar un registro actualizado de miembros. Sin embargo, la práctica política no refleja la precisión a la que obliga la norma, ya que hasta la fecha, son constantes las acusaciones de 
abultamiento en el padrón en las elecciones primarias de los partidos políticos, que optan a conveniencia entre la modalidad de padrón abierto, semiabierto y/o cerrado, dependiendo del nivel de competencia y hasta de posibles acuerdos informales entre facciones para favorecer a algún candidato en particular.

\section{Eje 3 - Estructura orgánica e instancias de toma de decisión}

Todos los partidos han fijado de forma clara y precisa el organigrama funcional, representativo y deliberativo en su normativa interna, tanto a nivel nacional como a nivel provincial y municipal. Sin embargo, la realidad partidista ha desvirtuado este organigrama de instancias de decisión. Por un lado, el excesivo centralismo deja inoperantes las instancias decisorias inferiores; y por otro, el personalismo y la cooptación patrimonial de los cargos, debilitan la institucionalidad partidista. Un indicador de este carácter más personal y menos institucional es que, en numerosas ocasiones, las casas de los dirigentes se erigen en sedes alternativas al partido, donde se deciden asuntos tan importantes como la reforma de los estatutos. A la cooptación personal se une la lucha entre corrientes por el control de los puestos de poder dentro del partido (Benito y Rosales, 2011: 18).

\section{Eje 4 - Reclutamiento de nuevos miembros}

Los partidos han delegado en un órgano específico las actividades proselitistas para la captación de miembros, descentralizando esta labor en las unidades organizativas más cercanas al ciudadano.

\section{B) Democratización}

\section{Eje 5 - Selección de autoridades partidarias}

Las contiendas internas para la selección de autoridades y la renovación de cargos en los partidos políticos dominicanos han sido objeto de controversia constante. Acusaciones de favoritismo entre tendencias, cismas internos y deserciones... que han acentuado aún más el 
faccionalismo endémico del sistema de partidos dominicano, producto de la tradición caudillista y la competencia entre liderazgos. Todos los partidos establecen el quién y el cómo en la elección de la autoridades máximas del partido a nivel central y también en el escenario provincial y municipal. Un escenario formal que parece convivir con mecanismos informales como el dedazo, la reserva de cuotas y el reparto de espacios entre tendencias.

\section{Eje 6 - Selección de candidatos a puestos de elección popular}

Los partidos establecen en su normativa interna el órgano encargado de selección de candidatos en los distintos escenarios, pero todos adolecen de cierta ambigüedad en cuanto al procedimiento de dicha selección. Las pasadas elecciones legislativas y municipales de mayo de 2010, pusieron de manifiesto no solo la flexibilidad de estos criterios, sino la importancia trascendental de otros tan importantes como los recursos disponibles, la negociación política y el transfuguismo. La cultura clientelar ha penetrado en los mecanismos informales de los procesos de selección de candidatos, representando un factor que erosiona la institucionalidad de los partidos políticos dominicanos. El transfuguismo y la negociación individual de los candidatos que buscan un lugar en la boleta electoral es otro de los mecanismos informales no contemplados en el proceso de selección de candidatos. El actual juego de alianzas también afecta al proceso de selección de candidatos, ya que la negociación para fijar los términos se basa en determinar cuántos escaños corresponden a cada partido en las provincias seleccionadas (Benito y Rosales, 2011: 21).

Los actores entrevistados expresaron su opinión al respecto de la influencia del dinero a la hora de aspirar a un cargo de elección popular:

(...) esto está asociado a su vez al crecimiento del clientelismo político y al ingreso con fuerza en los partidos de nuevos sectores sociales ligados a formas no tradiciones del ejercicio empresarial: bancas de apuestas y 
Diagnóstico del sistema de partidos en la República Dominicana

banqueros. Este sector ha entrado con un poder que no viene del ejercicio político con militancia, con ideología, con concepto... sino del dinero.

\section{Eje 7 - Definición de políticas}

El patrón de competencia interpartidista en la República Dominicana está hoy caracterizado por la débil presencia de vínculos programáticos entre ciudadanos y políticos, y por la ausencia de polarización ideológica. Los tres partidos mayoritarios han experimentado un proceso de progresiva derechización hasta el escenario actual, donde los tres compiten por ser "atrápalotodo" en el espectro de la derecha. La debilidad de los vínculos programáticos e ideológicos ha dejado espacio a otros de naturaleza más contingente, donde el personalismo o la eventualidad de las campañas, condicionarían hoy la decisión del votante dominicano. La ausencia de referentes programáticos en la competencia interpartidista dominicana, simplifica y allana el camino de las deserciones partidistas y el transfuguismo, donde la supervivencia institucional prima sobre la batalla electoral por determinar las políticas (Benito Sánchez, 2010: 765). De igual manera las alianzas entre partidos, a falta de referentes programáticos que sirvan de base a la implementación de políticas públicas consensuadas, se han centrado en concertar el acceso a la tarta del Estado. Las alianzas electorales se realizan para ganar, no para gobernar desarrollando un programa compartido de gobierno, sino para ocupar parcelas dentro de un Estado que se ofrece como premio y lograr el ansiado cargo de designación. Las percepciones de los actores entrevistados corroboran este marco informal de la actuación de los partidos dominicanos.

Las alianzas se han hecho alrededor de cuotas de poder y desprovistas de cualquier consideración de tipo programático. En nuestro país las alianzas están totalmente desvirtuadas. No discutimos en la negociación con una plataforma programática o ideológica. Si ustedes ven las noticias, lo que se está hablando ahora mismo es de posiciones nada más. En la campaña no se está hablando de proyectos. Aqui nadie está presentando nada. Los partidos no se acercan a la gente con una agenda política de 
avance, de crecimiento y de aporte a las comunidades. Predomina el interés particular. (Benito y Rosales, 2011: 23).

\section{Eje 8 - Inclusión: representación de grupos y sectores sociales}

Los partidos dominicanos cuentan con órganos especializados de trabajo, con cierta autonomía en su funcionamiento pero siempre bajo la coordinación y supervisión del Comité Político y la Secretaría de Organización. A pesar de esta reglamentación, las secretarías de la Mujer y de la Juventud no han asumido el rol de ser agentes activos en la definición de políticas de igualdad y de promoción, ni a lo interno del partido ni a nivel de proyecto de nación. Su función de movilización electoralista minimiza su responsabilidad de lograr que los partidos políticos, agentes de la representación, sean catalizadores de la mayor profundización democrática y de la construcción de una ciudadanía pluralista en el país. En la práctica, las secretarías de la Mujer de las diversas organizaciones partidistas funcionan como meros agentes de movilización en las contiendas eleccionarias, asignándoles tareas de logística y organizativas. Además, estos órganos han asumido funciones asistencialistas ayudando a las compañeras mujeres con asuntos como la muerte de un familiar o situaciones de desamparo de diversa índole... por lo que se reproduce en el ámbito partidario y público el tradicional reparto de roles y responsabilidades. A estas limitaciones que se derivan de una cultura machista y patriarcal, se suman los obstáculos del financiamiento y el voto preferencial. En situación muy similar se encuentran los jóvenes políticos, que resienten la falta de recursos y la resistencia de las viejas figuras del partido. La Secretaría de la Juventud se activa en período electoral, utilizando a los jóvenes de "llena guaguas". La falta de recursos impide que se presenten al electorado nuevas caras y nuevas ideas:

La participación de la juventud en los procesos se hace sumamente difícil por razones económicas. Aquel joven que esté en politica y tiene riquezas es por alguna herencia de sus padres, porque tengas sus propias empresas. Es por eso que nosotros vemos tanto derroche de millones de pesos, las 
Diagnóstico del sistema de partidos en la República Dominicana

candidaturas están carísimas ahora mismo, no hay oportunidad para la juventud pasary expresar otro proyecto. (Benito y Rosales, 2011: 25).

\section{Eje 9 - Disciplina partidaria}

Todos los partidos políticos establecen en sus estatutos un listado de faltas y sanciones. En todos se verifican las garantías mínimas de un enjuiciamiento democrático, ya que se consagran las garantías del debido proceso. La mayor debilidad de la normativa interna en materia de disciplina se refiere a la lealtad partidista. Aunque todos ellos sancionan aquellos que se aparten de la línea del partido en su actuación pública, no hay una especificación detallada de las situaciones en que tal situación se produce. Este limbo normativo es el escenario idóneo al fenómeno del transfuguismo que caracteriza la interacción partidista de los últimos años en la República Dominicana. En la actualidad, y en el ámbito legislativo, el escaño pertenece al legislador, por lo que cuando un legislador migra hacia otra fuerza partidista, este conserva su curul. El Anteproyecto de Ley de Partidos pretende poner fin a esta situación, otorgando la propiedad del escaño al partido.

\section{Eje 10 - Pluralismo: movimientos, corrientes y tendencias internas}

Ninguno de los partidos del estudio permite la formación de movimientos, corrientes o tendencias con autonomía ideológica, financiera y/o electoral, sin embargo, el faccionalismo hoy, lejos de ser reflejo de la democracia interna en el seno de las organizaciones, es un mal endémico producto de la tradición caudillista y la competencia feroz entre liderazgos y sus séquitos.

\section{Eje 11 - Capacitación y espacios para el debate y la deliberación}

Aunque todos los partidos establecen en sus estatutos un organismo especializado encargado de la formación política bajo de modalidad de Secretarías de Formación y Doctrina, la formación política no 
ocupa un lugar prioritario en la agenda de los mismos, la selección del candidato se determina por su capacidad de arrastre y no por su nivel de formación y compromiso partidario. Como reconocía uno de los miembros entrevistados:

No todas las candidaturas tienen que ser internas, sino que en la sociedad, en otras organizaciones hay gente que puede ser candidato, y que no necesariamente tienen que asumir al partido como su organización. Nosotros respetamos su independencia. Si después esa persona se convence y quiere entrar, tiene los brazos abiertos. (Benito y Rosales, 2011: 27)

\section{C) Transparencia INTERNA}

\section{Eje 12 - Control financiero y rendición de cuentas de la gestión financiera del partido}

La permisibilidad del sistema de financiamiento político en la República Dominicana es un indicador revelador de la complicada relación del dinero y la política en el país. La distensión de los controles en cuanto a los donantes privados - sin límite de cuantía ni obligación de registro y publicidad-, amenaza la integridad y autonomía del sistema político dominicano, favoreciendo el intercambio de favores entre los donantes y los políticos y condicionando la orientación de las decisiones públicas. Además de la presencia de los grupos de interés en el opaco escenario del financiamiento, el uso de recursos estatales en las campañas electorales afecta la participación de los partidos políticos dominicanos en condiciones de equidad. Salvo la prohibición de donaciones privadas de origen ilícito y de organismos extranjeros, no hay limitación alguna en cuanto a la cantidad recibida ni al tiempo que han de durar las actividades proselitistas, lo que ha sumido al país en una constante campaña electoral que alcanza proporciones descomunales. Esta laxitud también se refleja en la regulación interna de las finanzas del partido, y en la falta de previsión normativa interna en cuanto a la distribución racional/ funcional del presupuesto entre los órganos jerárquicos y las unidades 
descentralizadas. Pero sin duda la mayor de las lagunas en el control financiero de las fuerzas políticas es la ausencia de sanciones por parte de la Junta Central Electoral ante la no presentación de sus estados financieros. Esta falta de penalidad desvirtúa el sistema de control convirtiéndolo en obsoleto. Las percepciones de los actores permiten descifrar cómo las peculiaridades del sistema de financiamiento y control, condicionan el ejercicio de la política:

Va a ser dificil que la Ley de Partidos ponga límites... aqui es costumbre utilizar los recursos del Estado en las campañas. En los últimos años esto se ha desbordado, porque cuando colocas a un funcionario como candidato... esto es una carta abierta para que use los recursos públicos... y lo hacen sin miramientos y sin esconderlo. Los recursos privados al final a lo que llevan es a la corruptela... Si aquel me dio 10 millones, 20 millones hay que resarcírselo después, pasa factura". "La Cámara de Cuentas tendría que jugar un papel preponderante, que no sea solamente que llevaron unos papeles y dijeron lo que gastaron alli... hay que verificar si es verdad que lo gastaron y exigir a los candidatos que los recursos privados se conozcan.

En cuanto a las dificultades del quehacer partidario en las provincias y municipios, los actores revelan que la falta de financiamiento está trayendo a la política un gran número de outsiders, sin identidad política, precipitando la desideologización del sistema de partidos dominicano:

Ahora en el municipio presentamos una boleta electoral de banqueros, colmaderos, comerciantes... porque los dirigentes, los políticos, los que están preparados para dirigir el Estado no tienen capacidad económica. Tienen el liderazgo... pero viene un "Juan" con dinero y conquista, porque el elector está esperando que le den 100 pesos. 
Eje 13 - Legalidad interna, protección de los derechos de los miembros e instancias de apelación ante incumplimientos

Todos los partidos identifican en sus estatutos el órgano encargado de velar por el cumplimiento de los derechos y deberes de los miembros. Este marco normativo, sin embargo, es solo el escenario garante formal de los derechos de los miembros y de la legalidad partidaria, ya que el quehacer partidario muestra un escenario de incumplimientos reiterados, imposiciones extraestatutarias por parte de las corrientes dominantes a lo interno del partido y una creciente judicialización de las controversias internas. Los mayores agravios han tenido lugar con ocasión de la selección de candidatos y la conformación de la boleta electoral tras las alianzas. La práctica aliancista ha desvirtuado la competencia en las elecciones internas, ya que la reubicación de candidatos objeto del canje pre-electoral tiene preferencia sobre el puesto alcanzado por el candidato en las primarias internas. En las elecciones de mayo de 2010 se interpusieron 256 recursos ante la JCE, un fenómeno que llegó a poner en peligro la confección de la boleta en los plazos establecidos en la Ley, en espera por la inclusión de los candidatos definitivos.

\section{Tratamientos paliativos y algunas recetas para su modernización}

El diagnóstico presentado sobre la salud democrática de los partidos políticos dominicanos y la estructura de la competencia, permite delinear a grandes rasgos las debilidades de la democracia dominicana, en el actual contexto de rearticulación y redefinición de la élite política emergente:

- Democracia delegativa y electoralista

- Predominio en los partidos del particularismo sobre el interés general

- Orfandad ideológica y clientelismo 
Diagnóstico del sistema de partidos en la República Dominicana

- Autoritarismo

- Crecimiento económico sin redistribución

- Debilidad del Estado de derecho

- Politización de la administración pública

- Poca confianza de la ciudadanía en los partidos políticos

Los contextos de crisis y rearticulación como el que está viviendo la República Dominicana son, sin embargo, escenarios propicios para el cambio y puntos de inflexión creativos. En este sentido, los partidos políticos y sus dirigentes tienen por delante una agenda de desafíos $y$ oportunidades que afrontar en materia de institucionalización, democratización interna y transparencia (Benito y Lozano, 2011: 63):

1. Lograr un consenso interpartidario que impulse la aprobación de la Ley de Partidos y Agrupaciones Políticas. Es necesario en el país un marco normativo que dé respuesta a las mayores garantías y controles que exige la competencia partidista en democracia.

2. Reforma de los estatutos para que estos sean el marco normativo de todos los procesos y eventualidades de la vida del partido. Las lagunas normativas fomentan la discrecionalidad y atentan contra la institucionalidad partidaria. Será necesario un acercamiento entre lo formal y la práctica cotidiana.

3. Los partidos políticos son los articuladores claves de la representación política y como tales, deberán garantizar la representación en equidad de mujeres, jóvenes y otros sectores/grupos de la sociedad. La representación pluralista es condición necesaria de la calidad de la democracia.

4. Reactivar la formación política en el seno de sus organizaciones para afrontar el progresivo declive ideológico/programático. La ausencia de diferenciación ideológica deriva en una competencia personalista y particular, donde los líderes se imponen 
sobre los partidos. En ausencia de referentes partidistas, el clientelismo es la base de la movilización electoral. En el juego de alianzas, esta carencia se traduce en negociaciones para repartir espacios de poder y no en consensuar una agenda legislativa o de gobierno que garantice la gobernabilidad.

5. Reactivar los vínculos con las organizaciones y la militancia de base. Garantizar y respetar su participación en la toma de decisiones es condición necesaria de la democracia interna de los partidos.

6. Los representantes de los partidos políticos ante la JCE deben exigir que esta fiscalice y penalice la gestión financiera irregular de los partidos políticos. La parca regulación del financiamiento privado, sin topes ni obligatoriedad de publicidad, está generando una complicada relación entre dinero y política en el país con la entrada de empresarios políticos, y el más preocupante fenómeno del dinero procedente del narcotráfico.

7. Presentar al electorado dominicano un programa de interés colectivo, incluyente y abarcador, para recuperar su confianza en el que el partido presente a la sociedad su proyecto de nación más allá de intereses personales de facciones o grupos. El fortalecimiento de los partidos asegura la estabilidad del sistema político y pone freno a los liderazgos providenciales.

Afrontar estos retos modernizadores del sistema de partidos requiere del esfuerzo no solo de la clase política dirigente, sino de la presión de la sociedad civil más allá de la rutinaria cita con las urnas cada cuatro años. Una ciudadanía activa que reclame su legítimo espacio en la vida pública, fiscalice y sancione la actuación de sus políticos y defienda su papel en la definición de políticas.

\section{Una apuesta por los partidos y los políticos}

Desde 1978, en presencia de los caudillos y tras su desaparición, la fórmula de la supervivencia del sistema de partidos dominicano ha 
sido la combinación de: fragilidad institucional y fuerza electoral (Lozano 2010). Los partidos dominicanos son hoy más estables pero no más institucionalizados. El diagnóstico que sale ahora a la luz, es una útil herramienta que permitirá definir los retos y oportunidades de los partidos políticos dominicanos y sus dirigentes, y en consecuencia, diseñar estrategias de cambio realistas y eficaces. La calidad de la democracia dominicana, depende de la calidad de sus instituciones y de su liderazgo, ya que los partidos políticos son los articuladores clave de la representación y encargados de canalizar el conflicto hacia las instituciones. Con este propósito, iniciativas como el Programa de Formación y Gerencia Política han ocupado un lugar protagónico en materia de capacitación, promoviendo un cambio en la cultura política del país, en un espacio de deliberación interpartidista donde se fomenta el diálogo y la concertación ${ }^{2}$. Si bien el PFGP no suple la formación doctrinaria, competencia legítima de los propios partidos, empodera a los jóvenes líderes en el manejo eficiente y transparente de la gestión pública, profundiza sus conocimientos sobre la democracia y genera un cambio de patrones hacia el liderazgo democrático. Todos estos aportes, afectan positivamente la calidad de la democracia en República Dominicana en el medio plazo, ya que desde el año 2006, se han graduado en sus aulas cerca de 2,000 jóvenes, una generación que será protagonista del escenario político nacional y artífice del cambio.

Sin embargo, todo apunta a una nueva tendencia en las instituciones financiadoras de la cooperación en materia de gobernabilidad, que

2 El Programa de Formación y Gerencia Política es gestionado por tres prestigiosas instituciones de República Dominicana: el Movimiento Cívico Participación Ciudadana, el Centro de Gobernabilidad y Gerencia Social del Instituto Tecnológico de Santo Domingo (INTEC) y el Centro de Investigación y Estudios Sociales de la Universidad Iberoamericana (UNIBE). Cuenta con el apoyo de la Agencia de los Estados Unidos para el Desarrollo Internacional en la República Dominicana (USAID/DR). Este Programa apoya procesos de democratización en los partidos políticos, formando y entrenando a sus jóvenes líderes. Su actividad central son los Cursos de Formación sobre Liderazgo y Gerencia Política, que pretenden contribuir tanto a modernizar el sistema político como a una mejor y más cercana relación entre el sistema de partidos y la sociedad civil, afirmando así un nuevo y joven liderazgo democrático en el país. 
dirigen su foco de atención prioritario a la sociedad civil organizada. Si bien es cierto que contribuir a la mayor incidencia política de la sociedad civil es una loable conquista democrática, también resulta peligrosa la demagógica propensión a la satanización de los partidos políticos. El desempeño institucional se ha revelado decisivo en los procesos de consolidación democrática, ya que las instituciones lideran los procesos de modernización y en ellas se generan aspiraciones colectivas. Empoderar únicamente a la sociedad civil en contextos de fragilidad y debilidad institucional, podría desestabilizar la balanza de la gobernabilidad democrática en favor de la corporativización de la sociedad.

No está de más volver a recordar las palabras de Dante Caputo (PNUD, 2004: 20) frente al manido rechazo de los que ejercen la política $^{3}$ :

Estos políticos son los que han dado las luchas, los que han optado entre costos, los que han pagado con su prestigio u honor sus defectos o faltas. No tienen la pureza de quienes solo asumen el riesgo de opinar. Muchos tienen la sencilla valentía de pelear en un escenario donde, las más de las veces, lo que se confronta no son grandes ideas, sino pasiones y miserias. Algunos temen y abandonan, otros cometen errores y -de una u otra manera-pagan por ellos, pero una mayoría bizo algo más que opinar acerca de cómo deberían ser hechas las cosas. Lo intentaron, apostaron, perdieron, y muchos volvieron a intentarlo. Algunos con éxito. Nada bay aqui de reivindicación sentimental de los politicos, sino la sencilla advertencia de que la democracia no es una construcción idilica. Requiere de mujeres y hombres dispuestos a luchar en este turbulento territorio donde se desenvuelven los intereses y las pasiones, las luchas reales, que son las luchas de poder. La democracia se hace con la política, la única actividad que puede reunir la dura y maravillosa tarea de lidiar con la condición humana para construir una sociedad más digna.

3 PNUD (2004) La democracia en América Latina. Hacia una democracia de ciudadanos y ciudadanas.

454 Ciencia y Sociedad 2012; 37(4): 435-457 
Diagnóstico del sistema de partidos en la República Dominicana

\section{Bibliografía}

Benito Sánchez, A. B. (2010). "La política del poder: alianzas e interacciones partidistas estratégicas en República Dominicana”, en Revista de Ciencia Política, Santiago de Chile: Universidad Católica de Chile, Vol.30, Núm. 3.

Benito Sánchez, A. B. y Lozano, W. (2011). "Principales cambios y continuidades en la estructura de la competencia del sistema de partidos dominicano (1978-2010). En Programa de Formación y Gerencia Política (ed.), Diagnóstico sobre la situación del sistema de partidos en República Dominicana 2005-2010. Santo Domingo: USAID, IIDHCAPEL.

Benito Sánchez, A. B. y Rosales, R. (2011). "Marco normativo del sistema de partidos en República Dominicana: las reglas del juego partidario". [En Programa de Formación y Gerencia Política (ed.)], Diagnóstico sobre la situación del sistema de partidos en República Dominicana 2005-2010. Santo Domingo: USAID, IIDH-CAPEL.

Lozano, W. (2010). "Sistema de partidos y cambio democrático. Aproximaciones al caso dominicano". En Revista América Latina Hoy, Salamanca: Instituto de Iberoamérica de la Universidad de Salamanca, N. ${ }^{\circ}$ 6, diciembre.

PNUD (2004) La democracia en América Latina. Hacia una democracia de ciudadanos y ciudadanas. Nueva York: Alfaguara.

Programa de Formación y Gerencia Política (PFGP) (2011). Diagnóstico sobre la situación del sistema de partidos en la República Dominicana 2005-2010: análisis del marco normativo y visión de los actores. Santo Domingo: USAID, CAPEL, PFGP.

Rosales, R. y Valverde, R. (2006). Democratización de los partidos politicos en Bolivia, Chile y República Dominicana. Centro de Asesoría y Promoción Electoral del Instituto Interamericano de Derechos Humanos (IIDH-CAPEL). San José, Costa Rica. 


\section{Rafael Toribio}

Licenciado en Ciencia Política (UCM). Profesor universitario (UASD, INTEC, UNPHU), Ex rector del INTEC. Ha sido Coordinador Nacional del Plan Decenal de Educación (1990); director Ejecutivo del Proyecto para el Apoyo a Iniciativas Democráticas (1992); miembro de la Comisión de Verificación de las Elecciones de 1994; coordinador del Movimiento Participación Ciudadana (1997); miembro de la Comisión Centroamericana para la Reforma Educativa (2000); de la Comisión Presidencial para la Reforma de la Constitución (2002); consultor en el Plan Estratégico de Desarrollo de la Educación Dominicana (2003) y en el Plan Decenal de Salud (2006); coordinador del Foro Partidos Políticos-Sociedad Civil (2004); y director Ejecutivo Consejo Económico, Social e Institucional (2005). Responsable de la Coordinación General del PFGP (2006-2012). Actualmente es director del Centro de Gobernabilidad y Gerencia Social, CEGES-INTEC

Email: rafael.toribio@intec.edu.do

\section{Ana Belén Benito Sánchez}

Licenciada en Derecho (USAL), maestría en Administración Pública (UPR) y en Estudios Latinoamericanos (USAL), candidata a doctora en el Programa Procesos Políticos Contemporáneos (USAL). Ha sido investigadora en el Instituto de Iberoamérica, España (2008); becaria del Ministerio de Asuntos Exteriores 
y Cooperación (Cooperación Científica MAECAECID 2009-2011) y de la Fundación Carolina (2011) en República Dominicana. Coordinadora docente de los Cursos Especializados del PFGP (2011-2012) y consultora externa del PNUD (2008) y del Banco Mundial (2012). Actualmente es coordinadora académica del Centro de Gobernabilidad y Gerencia Social, CEGES-INTEC

Email: ana.benito@intec.edu.do

Recibido: 08/07/2012

Aprobado: 10/11/2012 
